\title{
COMPARISON OF BOND STRENGTH BETWEEN ACRYLIC BASED SOFT LINER AND TWO DIFFERENT DENTURE BASES (3DPRINTED AND CONVENTIONAL DENTURE BASE)
}

\author{
Mohamed Mahmoud Dohiem*
}

\begin{abstract}
Introduction: Soft liners used in case of sore or atrophied mucosa, alleviate inflamed mucosa and for obturators after maxillofacial surgery. but These liners have several problems such as the loss of softness, porosity and poor tear strength, which is of the most serious problems with soft denture liners is the failure of adhesion between the soft denture liner and the denture. That may be lead to failure as a result.
\end{abstract}

Material and methods: The samples were divided into two groups $(n=40)$ according to the type of denture base materials: Group I: 3D printed denture base with Acrylic based soft liner (Acrostone Dental \& Medical Supplies), Group II: heat cured acrylic denture base with Acrylic based soft liner (Acrostone Dental \& Medical Supplies). The samples were tested by shear applied by tensile mode of force. samples were tested by (Instron) the universal testing machine at a crosshead speed of $40 \mathrm{~mm} / \mathrm{min}$ until complete separation of soft-liner material from the acrylic plates. The maximum force at the point of failure leading to separation was recorded.

Result: Bond strength in Group I (acrylic soft liner with conventional heat cured denture base) showed a statistically significant difference when compare to group II (the acrylic based soft liner to $3 \mathrm{D}$ printed denture base) Shows $\mathrm{P}$ value of 0.000 .

CONCLUSION: Based on our study findings of this in vitro study, 3Dprinted denture base with acrylic based soft liners had statistically significant lower tensile bond strength values to the conventional heat cured one.

\section{INTRODUCTION}

One of the main purpose to treat dental patient is to option comfort and maximum function with the dental prosthesis and this can be done by using relining procedure that can be effective in even distribution of load on the denture-supporting area that decrease concentrations and increase retention of the prosthesis by engaging undercuts. ${ }^{1}$

These liners are used in case of sore or atrophied mucosa, alleviate inflamed mucosa and for

\footnotetext{
* Lecturer of Prosthodontics Oral and Dental Medicine, Zagaig University.
} 
obturators after maxillofacial surgery. ${ }^{1}$ but These liners have several problems such as the loss of softness, porosity and poor tear strength, which is of the most serious problems with soft denture liners that is lead to failure of adhesion between the soft denture liner and the denture ${ }^{2,3}$ These Bond failure cause a suitable surface for bacterial growth, plaque, and calculus formation.

Meanwhile The longevity of soft denture lining materials is a major problem since therefore; Effective bonding of these materials to the denture base is important for their success ${ }^{4}$

So A reliable bond between denture base and soft liner is required for the denture to function properly. ${ }^{5,6}$ These bond depend on type of liner and the denture base material

Polymethyl methacrylate (PMMA) resins have been the most popular denture base resins, as PMMA include excellent esthetic properties, adequate strength, low water sorption, low solubility, lack of toxicity, facility of repair, and construction by a simple technique, this is why Polymethyl methacrylate (PMMA) denture base has dominated the market for more than 50 years..$^{7-9}$ polymethyl methacrylate (PMMA) denture base constructed either Heat -cured or 3Dprinted rapid prototypes (additional methods) the Additive manufacturing is a process in which the final desired part is manufactured by adding multiple layers of material on top of one another ${ }^{10}$

Nowadays additive manufacturing offers several advantages compared to the subtractive methods.

Additive manufacturing can reduce waste material to almost $40 \%$, and they can shape structures of complex geometry unlike the subtractive methods which are limited by the milling burs diameter and the milling axes of the machine. It can also produce structures of bigger sizes while the milling machines are limited by the size of the block from which the structure is milled.
Another main advantage is the passive production where no force is exerted during manufacture, while in milling surface cracks can be introduced during hard machining. ${ }^{11}$ as digital and new technology now a days widely used therefore it's a must to evaluate shear bond strength between the conventional way (heat cured ) of acrylic resin and the new technology 3Dprinted way.

Therefore, the aim of this study was to evaluate shear bond strength (SBS) of self-cured Acrylic soft lining material with conventional heat cured denture base and 3D printed denture base

\section{MATERIALS AND METHODS}

\section{Test samples preparation}

The samples were divided into two groups $(n=40)$ according to the type of denture base materials:

Group I: 3D printed denture base with Acrylic based soft liner (Acrostone Dental \& Medical Supplies),

Group II: heat cured acrylic denture base with Acrylic based soft liner (Acrostone Dental \& Medical Supplies) Using blender (blender software $\mathrm{V}$ 2.83), a rectangular specimen was designed with a dimension of $(50 \cdot 10 \cdot 3) \mathrm{mm}$ resembling the dimensions of denture base material. Another rectangular specimen with a dimension of $(10 \cdot 10$ -3) mm was designed resembling the dimensions of soft-liner material. As seen in figure $1 \mathrm{a}, \mathrm{b}$

\section{Preparation of heat cured acrylic resin denture base samples}

Forty specimens of denture base materials were $3 \mathrm{D}$ printed in resin (EPAX resin for Epax 3d printer)

These samples were flasked and packed with heat-polymerizing resin (Denture Base Material; Vertex-Dental B.V.) then finished and polished. 
Preparation of $3 D$ printed acrylic resin denture base samples

Forty specimens of denture base materials were 3D printed in denture base resin (MMMOTH resin for Phrozen 3d printer). The resultant samples were finished by removing supporting arms, placed in the ultrasonic washer, cleaned by alcohol to remove excess monomers which may cause polymerization shrinkage of the denture and then was placed in the ultraviolet curing unit for 30 minutes for complete guide curing. As seen in figure 2.

\section{Application of soft liner}

Each two denture base resin samples were immersed in Putty rubber base (Zhermak, Italy), together with soft liner thickness plate to form putty mould which will provide space for the soft lining material after its removal as seen in figure 3

\section{Application of acrostone soft liner}

The specimens were cleaned and wiped with alcohol and allowed to dry. The acrostone powder and liquid monomer was mixed with appropriate water powder ratio as recommended by the manufacture and then applied in the soft-liner space in the Putty mould and left until complete setting

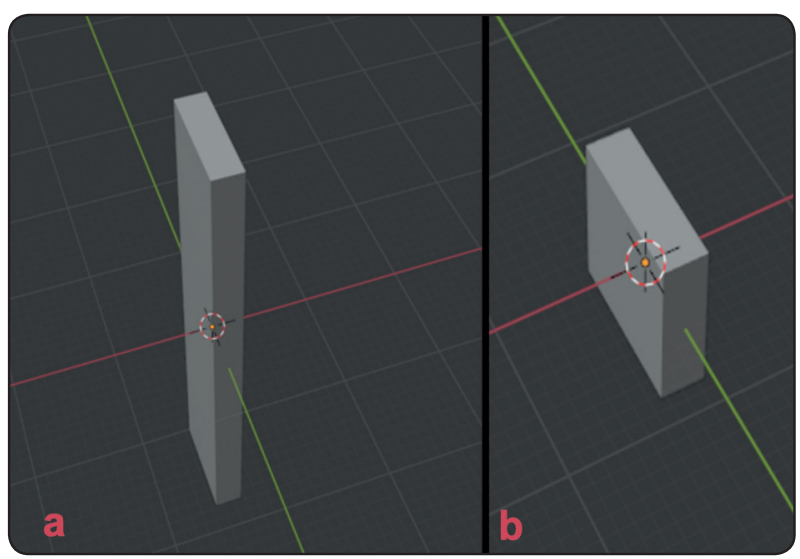

Fig. (1): designing of denture base and soft-liner samples. A: denture base samples $50 * 10 * 3 \mathrm{~mm}$. B: soft liner thickness sample $10 * 10 * 3 \mathrm{~mm}$ then the whole specimen was removed from the mould. As seen in figure 5

All specimens were stored in distilled water at a temperature of $37^{\circ} \mathrm{C}$ for a week. To mimic oral Conditions.

The samples were tested by shear applied by tensile mode of force. samples were tested by (Instron) the universal testing machine at a crosshead speed of $40 \mathrm{~mm} / \mathrm{min}$ until complete separation of soft-liner material from the acrylic plates. The maximum force at the point of failure leading to separation was recorded. As seen in figure 4

\section{Statistical methodology}

Data were collected and entered to the computer using SPSS (Statistical Package for Social Science) program for statistical analysis (ver 25)

No significance in the distribution of the variables was revealed by Kolmogorov-Smirnov test of normality, so the parametric statistics was adopted Comparisons were carried out between two studied independent normally distributed variables using independent sample $\mathrm{t}$ test. Data were described using mean, standard deviation and $95 \%$ CI of the mean.

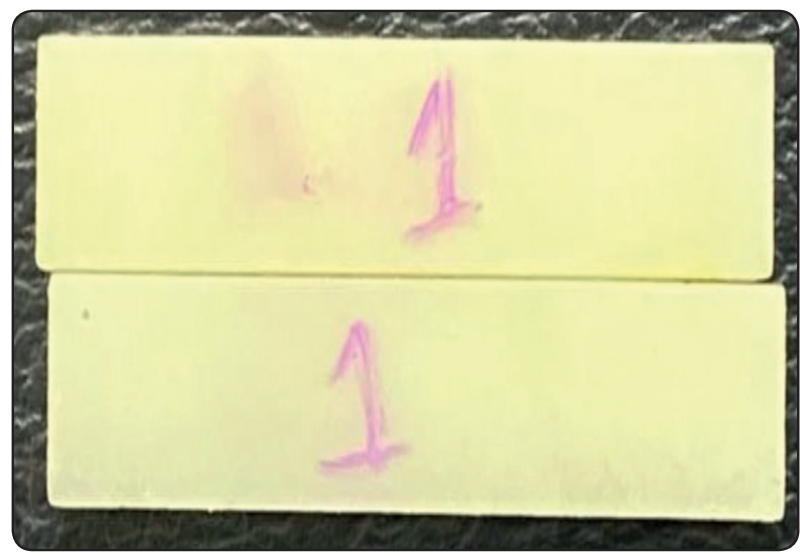

Fig. (2): 3D printed denture base samples 


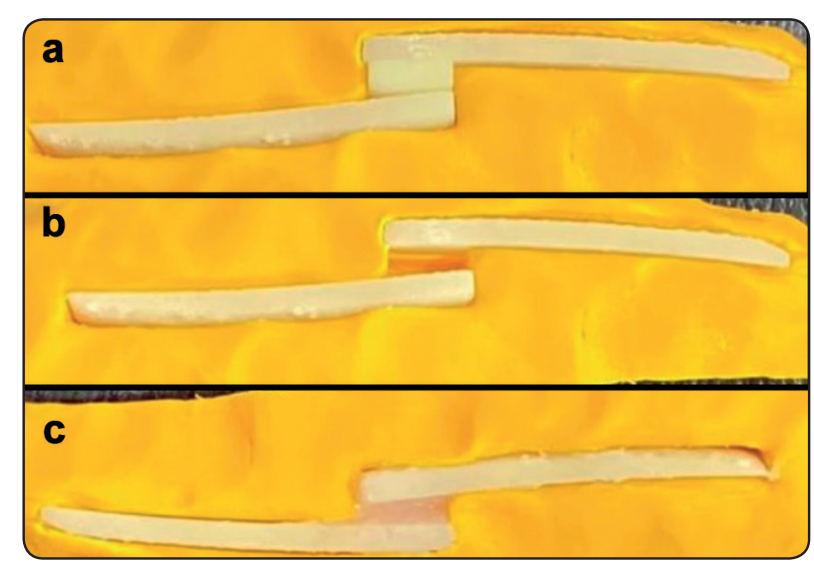

Fig. (3): steps of soft-liner application. A: mold for denture base samples with soft liner thickness plate. B: removal of soft-liner thickness plate. C: application of soft liner.

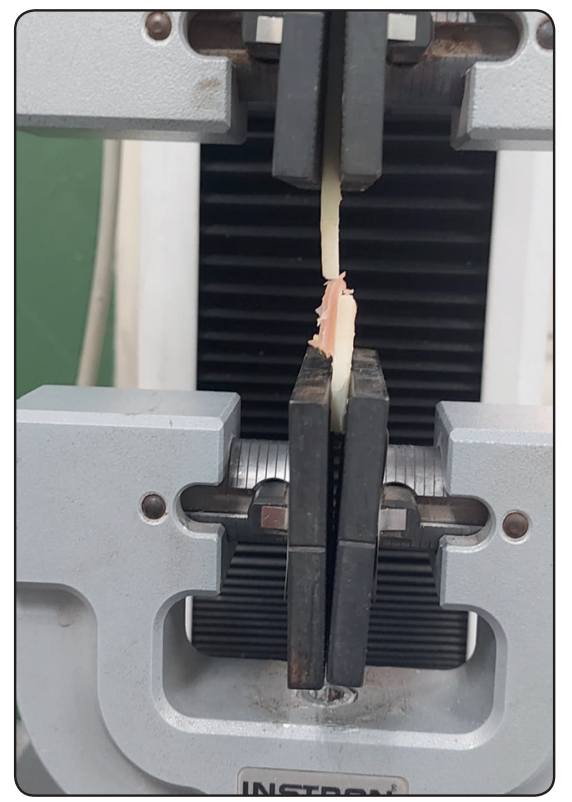

Fig. (4): Tensile shear bond test by universal testing machine.

\section{RESULTS}

In the present study, the bond strength while comparing group I with group, the result in group I was ranged from 64.092 to $65.11 \mathrm{~N}$ with a mean value of $64.601 \pm .509 \mathrm{~N}$ and in group II range from 38.95 to 40.2 with mean of $\mathbf{3 9 . 5 7 5 \pm . 6 2 5 N}$.

Showing significant difference in shear Bond strength in Group I (acrylic soft liner with conventional heat cured denture base) when compare to group II (the acrylic based soft liner to $3 \mathrm{D}$ ) with $\mathrm{P}$ value of $0.000 *$ (Table 1) figure 5 .

TABLE (1): Independent sample t-test comparing mean shear bond strength between resinbased soft-liner to heat cured and 3D printed denture base material

\begin{tabular}{cccc}
\hline & $\begin{array}{c}\text { Heat cured } \\
\text { denture base } \\
(\mathrm{M} \pm \mathrm{SD})\end{array}$ & $\begin{array}{c}\text { 3D printed } \\
\text { Denture base } \\
(\mathrm{M} \pm \mathrm{SD})\end{array}$ & P value \\
\hline $\begin{array}{c}\text { Shear bond } \\
\text { strength }\end{array}$ & $\mathbf{6 4 . 6 0 1 \pm . 5 0 9}$ & $\mathbf{3 9 . 5 7 5} \pm .625$ & $0.000 *$ \\
\hline
\end{tabular}

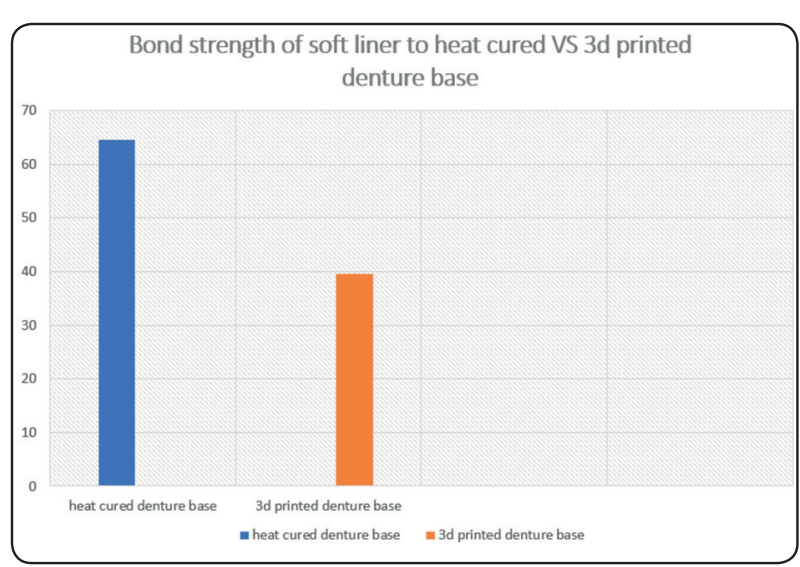

Fig. (5): Mean shear bond strength between resin-based softliner to heat cured and $3 \mathrm{~d}$ printed denture base material

\section{DISCUSSION}

Debonding of soft liners from the denture base is one of the major problems relined dentures. A durable bond between the two materials is a must to guarantee clinical success of the denture liner material. ${ }^{12}$

A lot of Factors affect the bond soft line material to denture base materials these factors are the chemical composition of the materials, thermal stresses in the oral cavity, liner thickness, nature of the adhesive, and tear strength of the resilient denture liner. ${ }^{13,14}$

In the present study, the shear bond strength for the two types of denture base material were tested at with acrylic soft liner between denture base 
Our results showed that shear bond strength of the conventional acrylic denture base material with soft acrylic soft liner was greater than 3D printers denture base with soft acrylic soft liner

The reason of this result among the two groups might be clarified by the difference in the chemical structure of the two denture bases in this study

This could be the result of Bonding of acrylic soft liner material compatibility with conventional denture base, which is due to the similarity in chemical structure between the soft liner and the continental denture base ${ }^{15,16,17}$

In addition, the conventional denture base specimens are fabricated from PMMA, while the printed denture base is made from a light-polymerizable denture base resin containing another additives that help in light polymerization also it must be placed in cured unit that may affect the surface energy of the $3 \mathrm{D}$ printed surface.$^{18}$

\section{CONCLUSION}

Based on our study findings of this in vitro study, the following conclusions were drawn:

3D printed denture base with acrylic based soft liners had statistically significant lower tensile bond strength values to the conventional heat cured one

\section{REFERENCES}

1. Lytle RB. Complete denture construction based on a study of the deformation of the underlying soft tissue. J Prosthet Dent. 1959;9:539.

2. Winkler Sheldon. Ed. Essentials of complete denture prosthodontics. Philadelphia. WB Saunders Co. 1979;130.

3. Mese A, Güzel KG UE. Effect of storage duration on tensile bond strength of acrylic or silicone-based soft denture liners to a processed denture base polymer. Acta Odontol Sca-nd. 2005;63:31-35.

4. Anil N, Hekimoglu C, Büyükbas N EM. Microleakage study of various denture liners by autoradiography: Effect of accelerated aging. J Prosthet Dent. 2000;84(4):394-399.

5. Aydin AK, Terzioglu H, Akinay AE, Ulubayram K HN.
Bond strength and failure analysis of lining materials to denture resin. Dent Mater. 1999;15:211-8.

6. Mutluay MM RI. Evaluation of bond strength of soft relining materials to denture base polymers. Dent Mater. 2007;23:1373-81.

7. Anusavice K PR. Phillip's science of dentalmaterials. 11th ed. W B Sauders. 2003.

8. Nejatian, T., Johnson, A. and Van Noort R. Reinforcement of Denture Base Resin. Adv Sci andTechnology. 2006;49:124-9.

9. Takamata, T., \& Setcos JC. Resin denture bases: review of accuracy and methods of polymerization. Int J Prosthodont. 1989;2(6):555-562.

10. Torabi, K., Farjood, E., \& Hamedani S. Rapid prototyping technologies and their applications in prosthodontics, a review of literature. J Dent. 2015;16(1):1.

11. Alharbi, N., Osman, R., \& Wismeijer D. Effects of build direction on the mechanical properties of 3D-printed complete coverage interim dental restorations. J Prosthet Dent. 2016;115(6):760-7.

12. Emmer TJ Jr, Emmer TJ Sr, Vaidynathan J VT. Bond strength of permanent soft denture liners bonded to the denture base. J Prosthet Dent. 1995;74:595-601.

13. Kulak-Ozkan Y, Sertgoz A GH. Effect of thermocycling on tensile bond strength of six silicone-based resilient denture liners. J Prosthet Dent. 2003;89:303-10.

14. McCabe JF, Carrick TE KH. Adhesive bond strength and compliance for denture soft lining materials. Biomaterials. 2002;23:1347-52.

15. Meng G, Chung K, Fletcher-Stark M ZH. Effect of surface treatments and cyclic loading on the bond strength of acrylic resin denture teeth with auto polymerized repair acrylic resin. J Prosthet Dent. 2010;103:245-52.

16. Kulak-Ozkan Y, Sertgos A GH. Effect ofthermocycling on tensile bond strength of six siliconesbased, resilient denture liners. J Prosthet Dent. 2003;89:303-10.

17. Emmer TJ, Emmer TJ, Vaidynathan J, Vaidynathan TK. Bond strength of permanent soft denture liners bonded to the denture base. J Prosthet Dent. 1995;74(6):595-601.

18. Awad AN, Cho S, Kesterke MJ. Comparison of tensile bond strength of denture reline materials on denture bases fabricated with CAD-CAM technology. J Prosthet Dent [Internet]. :1-7. Available from: https://doi.org/10.1016/j. prosdent.2021.06.047 